\title{
AVD \\ Best Cited Articles 2018
}

It is with a great pleasure to announce the top three most-cited AVD articles on Web of Science.

No. 1

\section{Review Article}

Visceral Artery Aneurysms and Pseudoaneurysms—Should They All be Managed by Endovascular Techniques?

Citations: 35

Alfredo C. Cordova and Bauer E. Sumpio

Published: 2013 (Vol. 6 No. 4: 687-693)

DOI: 10.3400/avd.ra.13-00045

No. 2

\section{Review Article}

Compression Therapy: Clinical and Experimental Evidence

Partsch $H$

\section{Citations: 34}

Published: 2012 (Vol. 5 No. 4: 416-422)

DOI: $10.3400 /$ avd.ra. 12.00068

\section{No. 3}

\section{Review Article}

Recent Advancement on Surgical Treatments for Lymphedema

\author{
Koshima I, Narushima M, Yamamoto Y, Mihara M, and Iida T
}

Citations: 29

Published: 2012 (Vol. 5 No. 4: 409-415)

DOI: $10.3400 /$ avd.ra. 12.00080

The ranks are based on the citation counts on Web of Science, as of the end of November 2018.

(cc) BY-NC-SA (C2018 The Editorial Committee of Annals of Vascular Diseases. This article is distributed under the terms of the Creative Commons Attribution License, which permits use, distribution, and reproduction in any medium, provided the credit of the original work, a link to the license, and indication of any change are properly given, and the original work is not used for commercial purposes. Remixed or transformed contributions must be distributed under the same license as the original. 